\title{
SOCIAL ADAPTATION STATUS OF SYRIAN REFUGEE PHYSICIANS LIVING IN TURKEY
}

\author{
Basri Furkan Dağcıoğlu', Aylin Baydar Artantaş ${ }^{2}$, Ahmet Keskin ${ }^{1}$, İrep Karataş Eray ${ }^{2}$, Yusuf Üstü1, Mehmet Uğurlu ${ }^{1}$ \\ ${ }^{1}$ Department of Family Medicine, Faculty of Medicine, Ankara Yildirim Beyazit University, Ankara, Turkey \\ ${ }^{2}$ Department of Family Medicine, Ankara Bilkent City Hospital, Ankara, Turkey
}

\begin{abstract}
SUMMARY
Objectives: Since the beginning of the civil war in Syria, over 3.5 million Syrians have fled to Turkey. Considering the massive burden of healthcare service needs of this population, the Turkish government has launched an initiative as employing Syrian doctors to provide health services to their citizens in Refugee Health Centres. In this study, we aimed to explore the social adaptation status of Syrian physicians living in Turkey using a structured questionnaire and the Social Adaptation Self Evaluation Scale (SASS).

Methods: Between November 2016 and April 2018, 799 physicians who participated in "Syrian Physicians' Adaptation Training" were enrolled in the study and underwent a structured questionnaire that questioned socio-demographic data and the SASS. The participants were divided into two groups as having poor and normal/high SASS scores. The binary SASS groups were compared with some demographic data.

Results: The median SASS score of the respondents was found as 43 (min. 10, max. 60, IQR 10) which can be accepted as normal. In the binary grouping, it was seen that 107 (13.39\%) participants had poor social adaptation, whereas $692(86.61 \%)$ participants had normal or high social adaptation scores. The physicians who were certain about not going back to Syria had significantly higher SASS scores.

Conclusion: The social adaptation scores of the Syrian physicians were considerably high. The adaptation status was found to be associated with some characteristics like living in Turkey for a long time and having pre-knowledge about the Turkish healthcare system.
\end{abstract}

Key words: Syrian refugees, refugee physicians, social adaptation, SASS

Address for correspondence: B. Furkan Dağcıoğlu, Ankara Yildirim Beyazit University, Faculty of Medicine, Department of Family Medicine, Üniversiteler mah. İhsan doğramacı blv. 06800 Bilkent/Çankaya Ankara, Turkey. E-mail: bfurkan@gmail.com

https://doi.org/10.21101/cejph.a5955

\section{INTRODUCTION}

People who live abroad, in other than their country of residence, face various difficulties in almost every part of the world. One of them is the problems experienced in receiving health care. In many host countries, refugees cannot be provided with adequate health services due to reasons such as xenophobia, discrimination, language barriers, and inadequate health personnel (1-3).

Since the beginning of the civil war in Syria, over 400,000 people have died, and more than a half of the total population have been forced to leave their homes (4). Therefore, over 3.5 million Syrians have fled to Turkey (5). This mass movement starting from the year 2011 and already going on, has expectedly influenced the social life in Turkey, considering that the total number of Syrians who resettled in the third countries after coming to Turkey is only about 16,000 within the years 2014-2019 (6). The refugees coming from Syria have been recognized in "temporary protection" status by special legislations, which gives many rights in terms of health, education, working, etc. (7).

With the initiative led by the Turkish government, it was ensured that Syrian doctors were employed under special conditions (5). Based on the regulation (Regulation on work permits for foreigners under temporary protection 2016/8375), Syrians were allowed to work in Turkey under specific circumstances (7).
In this context, an attempt was made to allow Syrian doctors to provide health ser-vices to their citizens in Refugee Health Centres, where the refugees can have an extensive healthcare service without any cost (2). In this way, the language barrier in the health service is eliminated by physicians who speak the same language as the patients, and it is planned to minimize the extra load that more than 3.5 million refugee population will bring to the Turkish health system $(8,9)$. Syrian physicians to be employed in the health sector were planned to be trained in cooperation with the World Health Organization (WHO) and the Turkish Ministry of Health (10). Theoretical and practical training programmes and educational contents have been prepared within the scope of the "Adaptation Training of Syrian Physicians Project" programme in order to ensure the adaptation of physicians to the process, in cooperation with Ankara Yildirim Beyazit University, Department of Family Medicine. A total of 1,095 physicians participated in this training (10).

It should be kept in mind that the Syrian physicians who are employed within this project are struggling with the problems brought by the refugee status like the other citizens who fled the Syrian civil war. Therefore, it is obvious that the social adaptation levels of more than 1,000 Syrian physicians who take refuge in Turkey can affect the quality of the service that is provided for the refugees (11). 
Social functioning, which is essential as much as physical functioning, can be defined as an individual's interactions with their environment and the ability to fulfill their role within such environments as work, social activities, and relationships with partners and family (12). This concept is known to be associated with depression and some other psychiatric conditions, yet it is a diverse notion (12-14). Considering the tender situation of refugees who have experienced a civil war and have been forced to leave their country, the importance of social adaptation emerges once more $(2,11)$.

In this study, we aimed to explore the social adaptation status of Syrian physicians living in Turkey using a structured questionnaire and the Social Adaptation Self Evaluation Scale (SASS), following the idea that it may affect the quality of the service provided by them. This study will probably be the first example of the social assessment of physicians who offer health services to migrants that are forced to leave their countries, although they are also migrants themselves.

\section{MATERIALS AND METHODS}

Between November 2016 and April 2018, 1,095 physicians who participated in "Syrian Physicians' Adaptation Training" formed the research universe. Among these, 799 physicians who accepted to participate in the study by reading the informed consent form and who were able to read, write and converse in English adequate enough to maintain the minimum standards to fill the forms, underwent a structured questionnaire that questioned socio-demographic data and the Social Adaptation Self Evaluation Scale (SASS) as well. All survey forms were in English.

\section{Social Adaptation Self Evaluation Scale}

The SASS, a non-disease specific self-evaluation scale, which was developed by Bosc et al. in 1997, questions four main areas of social functioning: work, leisure, family, and social environment and organizing them $(15,17)$. The scale consists of 21 questions, and a score of $0-3$ can be taken for each question. Table 1 shows the subject of each item (16). Since only one of the first 2 questions can be answered, the scoring is done on 20 questions, and the total score can theoretically vary from 0 to 60 . Higher scores mean better social adaptation, whereas 0-34 points may be accepted as poor adaptation, and 35 and higher scores may be considered as normal or high social adaptation $(12,17)$. The SASS was preferred because it measures social motivation and social support in direct and indirect ways, which is easy to use and validated on depressive populations $(12,17,18)$.

\section{Statistical Analysis}

The data obtained from the surveys were transferred to the IBM SPSS v.22 package program. Frequencies were obtained for descriptive data. The normal distribution of data was examined by the Shapiro-Wilk test. Demographic data were given in numbers and percentages or median, minimum, maximum values, and Inter Quartile Range (IQR). In terms of total SASS scores, the participants were divided into two groups as having poor social adaptation scores and having normal/high scores, accepting 35 points as
Table 1. Subjects of each item of SASS

\begin{tabular}{|l|}
\hline 1. Job interest \\
\hline 2. Homework interest \\
\hline 3. Work enjoyment \\
\hline 4. Interest in hobbies \\
\hline 5. Quality of spare time \\
\hline 6. Family-seeking behaviour \\
\hline 7. Family relationship quality \\
\hline 8. Gregariousness \\
\hline 9. Relationship-seeking behaviour \\
\hline 10. External relationship quality \\
\hline 11. External relationship appreciation \\
\hline 12. Social attractiveness \\
\hline 13. Social compliance \\
\hline 14. Community involvement \\
\hline 15. Social inquisitiveness \\
\hline 16. Intellectual interest \\
\hline 17. Communication difficulties \\
\hline 18. Rejection sensitivity \\
\hline 19. Vainness \\
\hline 20. Difficulties in coping with resources \\
\hline 21. Control of surroundings \\
\hline
\end{tabular}

the cut-off value. In comparison of categorical variables and the binary SASS grouping, the chi-square test and adjusted residual analysis were preferred. Odds ratio values were calculated for the significant variables. The logistic regression model was built with the enter method in order to evaluate co-variates adjusted for the age and gender factors. Spearman's Rho correlation test was performed for correlation analysis. For statistical significance, the value of $\mathrm{p}<0.05$ was accepted as the limit.

\section{RESULTS}

The median age of the participants was 40 years (min. 24, max. 75 , IQR 15). The median value of the child number of families (who had children) was 3 (min. 1, max. 10, IQR 2).

Among the participants who answered the question $(n=560)$, the median duration of living in Turkey was 2 years (min. 0.08 , max. 12, IQR 3). Among these, 9.3\% $(n=52)$ of them were living in Turkey for less than 1 year, $64.3 \%(n=514)$ of them were living for less than 5 years, and $8.2 \%(n=46)$ of them were living for 5 years or longer. These 3 groups were found to be similar in terms of SASS score binary grouping $\left(\mathrm{p}=0.538, \chi^{2}=1.241\right)$. The median duration of the professional experience of the participants was 13 years (min. 0, max. 50, IQR 13).

It was found that $30.71 \%$ of the participants were general practitioners. In terms of specialization, almost all branches were available, although the most common branches were paediatrics (9.14\%), orthopedics $(6.60 \%)$, internal medicine $(5.84 \%)$, general surgery $(4.70 \%)$, and gynaecology and obstetrics (4.70\%). When we analyzed the specialties of the physicians who thought that 
Table 2. Relationship of socio-demographic data with SASS score grouping

\begin{tabular}{|c|c|c|c|c|c|c|}
\hline \multirow{2}{*}{ Variables } & \multirow{2}{*}{$\mathrm{n}$} & \multirow{2}{*}{$\%$} & \multirow{2}{*}{$\begin{array}{l}\text { Poor social } \\
\text { adaptation }\end{array}$} & \multirow{2}{*}{$\begin{array}{c}\text { Normal or high } \\
\text { social } \\
\text { adaptation }\end{array}$} & \multicolumn{2}{|c|}{ Relationship with SASS groups } \\
\hline & & & & & $x^{2}$ & $\mathrm{p}$-value \\
\hline \multicolumn{7}{|l|}{ Gender $(n=797)$} \\
\hline Female & 162 & 20.33 & 25 & 137 & \multirow{2}{*}{0.80} & \multirow{2}{*}{0.371} \\
\hline Male & 635 & 79.67 & 81 & 554 & & \\
\hline \multicolumn{7}{|l|}{ Marital status $(n=794)$} \\
\hline Married & 692 & 87.15 & 95 & 597 & \multirow{2}{*}{0.67} & \multirow{2}{*}{0.414} \\
\hline Other (single, widowed, divorced) & 102 & 12.85 & 11 & 91 & & \\
\hline \multicolumn{7}{|l|}{ Family status $(n=794)$} \\
\hline Core family & 665 & 83.75 & 93 & 572 & \multirow{4}{*}{3.82} & \multirow{4}{*}{0.282} \\
\hline Extended family & 61 & 7.68 & 8 & 53 & & \\
\hline Alone & 54 & 6.80 & 3 & 51 & & \\
\hline Other & 14 & 1.76 & 3 & 11 & & \\
\hline \multicolumn{7}{|l|}{ Children status $(n=797)$} \\
\hline Family with child & 678 & 85.07 & 93 & 585 & \multirow{2}{*}{0.69} & \multirow{2}{*}{0.408} \\
\hline Family without child & 119 & 14.93 & 13 & 106 & & \\
\hline \multicolumn{7}{|l|}{ Having baby under 1 year of age $(n=670)$} \\
\hline Yes & 150 & 22.39 & 17 & 133 & \multirow{2}{*}{0.94} & \multirow{2}{*}{0.333} \\
\hline No & 520 & 77.61 & 75 & 445 & & \\
\hline \multicolumn{7}{|l|}{ Place of residence $(n=783)$} \\
\hline City centre & 595 & 75.99 & 81 & 514 & \multirow{3}{*}{1.35} & \multirow{3}{*}{0.508} \\
\hline County & 158 & 20.18 & 23 & 135 & & \\
\hline Village & 30 & 3.83 & 2 & 28 & & \\
\hline Status of the house of living $(n=771)$ & & & & & & \\
\hline Renter & 716 & 92.87 & 90 & 626 & & \\
\hline Owner & 31 & 4.02 & 7 & 24 & 280 & 0400 \\
\hline Living in the house of a relative/friend, etc. & 18 & 2.33 & 3 & 15 & 2.05 & 0.400 \\
\hline Other & 6 & 0.78 & 1 & 5 & & \\
\hline Specialty $(n=788)$ & & & & & & \\
\hline General practitioner & 242 & 30.71 & 34 & 208 & 022 & 0638 \\
\hline Specialist & 546 & 69.29 & 70 & 476 & 0.22 & 0.050 \\
\hline Primary care experience $(n=699)$ & & & & & & \\
\hline Yes & 564 & 80.69 & 76 & 488 & 165 & 020 \\
\hline No & 135 & 19.31 & 24 & 111 & $1.0 \mathrm{~J}$ & 0.200 \\
\hline Having knowledge about Turkish healthcare & $(n=7$ & & & & & \\
\hline Yes & 180 & 25.39 & 16 & 164 & & \\
\hline No & 529 & 74.61 & 85 & 444 & 0.01 & 0.017 \\
\hline Can adapt to work in refugee health centres? & & & & & & \\
\hline Yes & 606 & 77.00 & 71 & 535 & & \\
\hline No & 37 & 4.70 & 6 & 31 & 4.45 & 0.108 \\
\hline Partially & 144 & 18.30 & 26 & 118 & & \\
\hline Planning to go back to his/her own country ( & & & & & & \\
\hline Yes or perhaps & 483 & 61.29 & 81 & 402 & & \\
\hline No & 305 & 38.71 & 24 & 281 & 12.03 & $<0.001$ \\
\hline
\end{tabular}


they could not adapt to work in Refugee Health Centres $(n=37)$, most of them were from various surgical branches $(48.65 \%)$ and others were from internal branches $(21.62 \%)$, general practitioners (10.81\%), and unspecified specialties (18.92\%). Among the investigated socio-demographic data of the participants, only having knowledge about the Turkish healthcare system and not planning to turn back to the origin country were found to be associated with higher SASS scores (Table 2). The odds ratios for these variables were 1.96 and 2.36, respectively (Table 3).

The median SASS score of the respondents was found as 43 (min. 10, max. 60, IQR 10). In the binary grouping according to the cut-off point of 35, it was seen that 107 participants $(13.39 \%)$ showed poor social adaptation, whereas 692 participants (86.61\%) showed normal or high social adaptation scores. SASS score distribution is given in Figure 1 and Figure 2.

While evaluating variables of the age, number of children, duration of living in Turkey, and the duration of professional experience, it was found that social adaptation status was slightly correlated with the median duration of living in Turkey. Other variables had no significant correlation with SASS scores (Table 4).

In the logreg model built with parameters that affect binary SASS scores grouping, it has been observed that being determined about not returning to the country of origin has the most noticeable effect on the scores, and this effect was independent of age and gender (Table 5).

\section{DISCUSSION}

This study, which is held by a group of researchers who had official permission for conducting research on this special group, reveals some interesting results. One of the unique aspects of this research is that it was the first research conducted on such a large group of refugee physicians.

When the general SASS scores of the participants were examined, it was observed that the majority of them did not experience serious problems with social adaptation, although most of them were living in Turkey only for a few years and most of them had to leave their relatives and properties in Syria (17). The median SASS score of the participants was similar to the scores of the normal population given in several studies $(17,19-22)$. This interesting finding may be associated with the wide social rights provided by the Turkish government, in the fields like healthcare, education, labour, etc., as well as other facilitating factors like the official TV channel broadcasting in Arabic language (TRT Arabi) and the positive attitude of Turkish citizens towards Syrian refugees, arising from the common historical and cultural roots (23-25). In the literature, ethnic discrimination was found to be endemic in the national health services, especially against migrants and ethnic minority candidates (3). In contrast with this situation, the similarity between Syria and Turkey in terms of religion, culture and social texture, especially in some cities

Table 3. Relationship between higher social adaptation scores and various categorical variables

\begin{tabular}{|c|c|c|c|c|c|}
\hline & \multirow{2}{*}{$x^{2}$} & \multirow{2}{*}{$\mathrm{p}$-value } & \multirow{2}{*}{ OR } & \multicolumn{2}{|c|}{$95 \% \mathrm{Cl}$} \\
\hline & & & & Lower & Upper \\
\hline Having knowledge about Turkish healthcare system & 5.67 & 0.017 & 1.96 & 1.11 & 3.45 \\
\hline Not planning to return to own country & 12.83 & $<0.001$ & 2.36 & 1.46 & 3.81 \\
\hline Experienced working in any job other than his/her own profession & 0.95 & 0.329 & 0.73 & 0.40 & 1.36 \\
\hline Had worked in any other country before & 0.52 & 0.470 & 1.38 & 0.58 & 3.30 \\
\hline
\end{tabular}

Table 4. Correlation between some continuous variables and SASS scores

\begin{tabular}{|l|c|c|}
\hline & Spearman's Rho & p-value \\
\hline Age & 0.017 & 0.632 \\
\hline Number of children & -0.012 & 0.729 \\
\hline Duration of living in Turkey & 0.088 & 0.038 \\
\hline Duration of professional experience & 0.021 & 0.559 \\
\hline
\end{tabular}

Table 5. Logistic regression analysis of SASS scores affecting factors

\begin{tabular}{|c|c|c|c|c|}
\hline & \multirow{2}{*}{ p-value } & \multirow{2}{*}{ OR } & \multicolumn{2}{|c|}{$95 \% \mathrm{Cl}$} \\
\hline & & & Lower & Lower \\
\hline Age & 0.996 & 1 & 0.98 & 1.02 \\
\hline Gender & 0.346 & 0.78 & 0.46 & 1.31 \\
\hline Having knowledge about Turkish healthcare system & 0.054 & 1.82 & 0.99 & 3.34 \\
\hline Not planning to return to own country & 0.001 & 2.40 & 1.43 & 4.03 \\
\hline
\end{tabular}

Nagelkerke $\mathrm{R}^{2}=0.054$ 


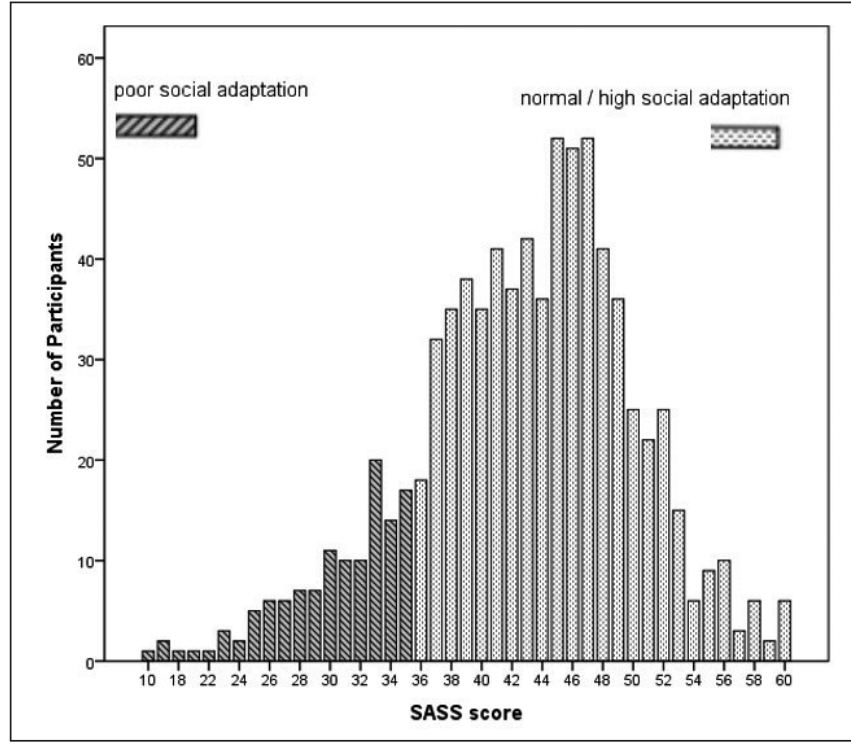

Fig. 1. Distribution of SASS scores of participants.

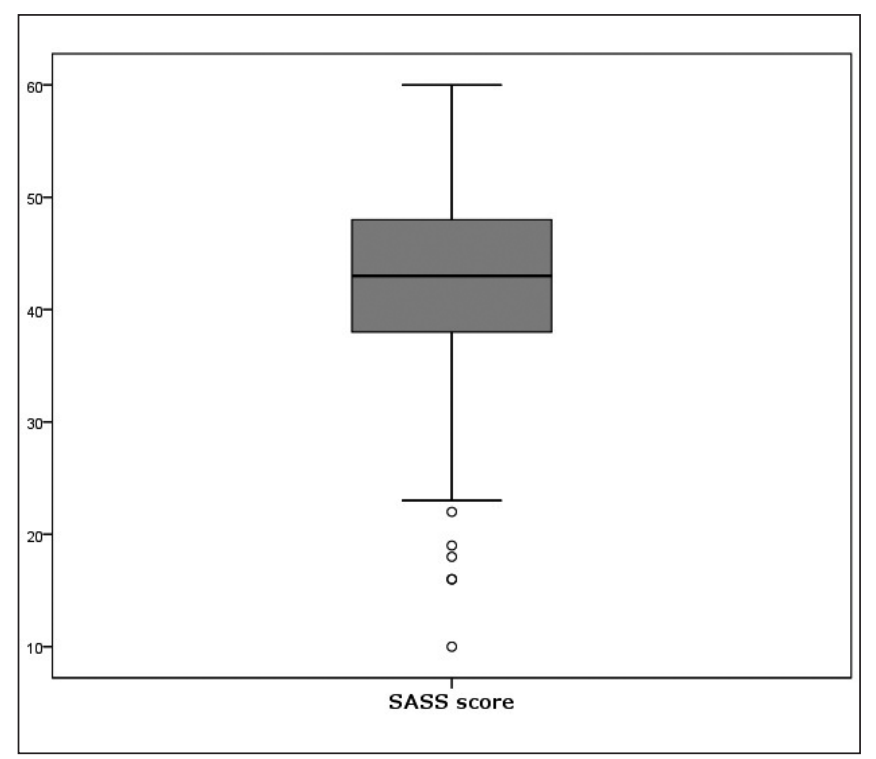

Fig. 2. Boxplot graph for SASS scores distribution.

of Turkey like Hatay and Gaziantep (where the Syrian refugees mostly live in), may have facilitated the adaptation process (26).

In terms of medical specialties, the largest proportion belonged to general practitioners, which was very coherent with the primary objectives of the Turkish government about the healthcare services provided for the refugees (2). Independent from medical branches, all the Syrian physicians were intended to be employed in the primary care facilities at first. Although it can be inferred that this may have a negative impact on the branch experts, unexpectedly, the majority of physicians thought that they could adapt to work in primary care. Mostly the surgeons of various branches had some doubts about adapting to work in primary care, nevertheless, almost all still wanted to try it. One of the pull factors here should be the opportunity to serve their citizens in the government facilities in a legal way, besides living on.
Because, according to migration theorists, the major forces that drive to migration can be categorized as environmental, social, political/legal, economic, historic, and cultural motivations (27). Interestingly, in our study population, it can be assumed that all these factors may have played a role as well. Besides, the high levels of motivation for working in Turkey may have raised the scores of social adaptation.

It was observed that having pre-knowledge about the healthcare system of the host country and being decisive about not returning home were associated with higher social adaptation scores. It can be thought that having knowledge may eliminate uncertainty, which is a huge reason for anxiety. On the other side, the direction of causality is unclear in the latter situation, which we cannot say whether higher social adaptation makes people decisive about staying in the new country or vice versa. Nonetheless, we observed that the longer the participants live in Turkey, the more social adaptation can be achieved. What is more, many participants were living in Turkey for a long time, up to 12 years, which can be another reason for high social adaptation scores. For this reason, it can be inferred that social adaptation requires time, which means the process should be carried out with patience and tolerance (28).

\section{Limitations}

In our study, most of the participants had never experienced working in another country before. Although we did not find any association with social adaptation status, we should remember the limitation that we did not evaluate the duration of the working abroad experience. Further studies may reveal the real effect of this phenomenon on social adaptation.

Another limitation of our study is that we did not evaluate the depression status of the participants. Although the Social Adaptation Self Evaluation Scale is well-validated in depressed populations in multiple languages, we could see no evidence of prior application to a refugee population. Certainly, refugee populations carry high burdens of mental illness, but they are not the same as a depressed population. Considering the close relationship between depression and social functioning, psychiatric assessment of this specific population might be valuable (29).

Lastly, the implementation of SASS in English instead of native language might have influenced the scores. The main reason for this problem is that no validated Arabic version of SASS was found in the literature. Although it was subjectively observed that most of the participants of the adaptation training knew English and not being fluent in English was a minor reason for rejecting participation in the study; the reasons for rejection were not explored explicitly.

\section{CONCLUSIONS}

Considering the potential of the Syrian physicians who had immigrated to the world's many countries - especially in Europe - not being sufficiently appreciated, Turkey's leadership on this initiative can be considered as an example for other countries (30). Ensuring Syrian doctors to serve their citizens can contribute to their social adaptation status, which means more effective use of human resources in the healthcare system. In this context, the 
social adaptation status of these doctors should be considered, for it may affect the quality of the service provided by them. Future studies investigating the effects of receiving health care from their citizens on the adaptation of refugees will shed light on another important aspect of this issue.

\section{Conflict of Interests}

None declared

\section{Adherence to Ethical Standards}

Ethics approval was taken from the local Ethics Committee (approval number 21.11.2018-09). Official permission procedures with government institutions were completed subsequently (Ministry of Interior Affairs, General Directorate of Immigration Management, Turkey: no. 62103649604.02.02-1366 [2019])

\section{REFERENCES}

1. Montgomery E, Foldspang A. Discrimination, mental problems and social adaptation in young refugees. Eur J Public Health. 2008;18(2):156-61.

2. Oda A, Tuck A, Agic B, Hynie M, Roche B, McKenzie K. Health care needs and use of health care services among newly arrived Syrian refugees: a cross-sectional study. CMAJ Open. 2017;5(2):E354-8.

3. Stewart E. A bitter pill to swallow: obstacles facing refugee doctors in the UK. New issues in refugee research. 2003;(96):1-23.

4. BBC. Illustrated: War in Syria in its 8th year [Internet]. BBC News Turkey; 2018 [cited 2020 Feb 23]. Available from: https://www.bbc.com/ turkce/haberler-dunya-43414137. (In Turkish.)

5. Food and Agriculture Organization of the United Nations. Turkey Syrian refugee resilience plan 2019-2020. Rome: FAO; 2019.

6. Republic of Turkey, Ministry of Interior, Directorate General of Migration Management. Statistics. Temporary protection. Resettlement of Syrians in the 3rd countries within 2014-2019 [Internet]. Ankara: Directorate General of Migration Management; 2019 [cited 2020 Feb 23]. Available from: https://en.goc.gov.tr/temporary-protection 27.

7. Regulation on work permits for foreigners under temporary protection, (2016/8375).

8. İçduygu A, Simșek D. Syrian refugees in Turkey: towards integration policies. Turk Policy Q. 2016;15(3):59-69.

9. Döner P, Özkara A, Kahveci R. Syrian refugees in Turkey: numbers and emotions. Lancet. 2013;382(9894):764

10. World Health Organization. World Refugee Day: WHO training enables Syrian doctors and nurses to provide health care in Turkey [Internet]. WHO; 2017 [cited 2020 Feb 23]. Available from: http://www.euro.who. int/en/countries/turkey/news/news/2017/06/world-refugee-day-whotraining-enables-syrian-doctors-and-nurses-to-provide-health-care-inturkey.

11. Jefee-Bahloul H, Bajbouj M, Alabdullah J, Hassan G, Barkil-Oteo A. Mental health in Europe's Syrian refugee crisis. Lancet Psychiatry. 2016;3(4):315-7.
12. Bosc M. Assessment of social functioning in depression. Compr Psychiatry. 2000;41(1):63-9.

13. Paykel ES, Weissman MM, Prusoff BA. Social maladjustment and severity of depression. Compr Psychiatry. 1978;19(2):121-8.

14. Leader JB, Klein DN. Social adjustment in dysthymia, double depression and episodic major depression. J Affect Disord. 1996;37(2-3):91-101.

15. Möller HJ. Rating depressed patients: observer- vs selfassessment. Eur Psychiatry. 2000;15(3):160-72.

16. Bech P, Lunde M, Unden M. Social Adaptation Self-evaluation Scale (SASS): psychometric analysis as outcome measure in the treatment of patients with major depression in the remission phase. Int J Psychiatry Clin Pract. 2002;6(3):141-6.

17. Bosc M, Dubini A, Polin V. Development and validation of a social functioning scale, the Social Adaptation Self-evaluation Scale. Eur Neuropsychopharmacol. 1997;7 Suppl 1:S57-70.

18. Tse WS, Bond AJ. Relationship between baseline cortisol, socia functioning and depression: a mediation analysis. Psychiatry Res. 2004;126(3):197-201.

19. Farokhnezhad Afshar P, Foroughan M, Vedadhir A, Ghazi Tabatabaie M. Psychometric properties of the Persian version of Social Adaptation Self-evaluation Scale in community-dwelling older adults. Clin Intery Aging. 2017; 12:579-84.

20. Akkaya C, Sarandöl A, Esen Danaci A, Sivrioğlu EY, Kaya E, Kirli S. Reliability and validity of the turkish version of the Social Adaptation Self-Evaluation Scale (SASS). Turk J Psychiatry. 2008;19(3):292-9.

21. Ueda N, Suda A, Nakagawa M, Nakano H, Umene-Nakano W, IkenouchiSugita A, et al. Reliability, validity and clinical utility of a Japanese version of the Social Adaptation Self-evaluation Scale as calibrated using the Beck Depression Inventory. Psychiatry Clin Neurosci. 2011;65(7):624-9.

22. Tse WS, Bond AJ. Psychometric analysis of the Chinese version of Social Adaptation Self-evaluation Scale (C-SASS). Psychiatry Res. 2007;153(3):277-81.

23. Allen R. Benefit or burden? Social capital, gender, and the economic adaptation of refugees. Int Migr Rev. 2018;43(2):332-65.

24. Ahsan S. Providing medical relief in Syria's conflict. Lancet. 2013;381(9866):523-4.

25. Aras B, Köni H. Turkish-Syrian relations revisited. Arab Stud Q. 2002;24(4):47-60

26. Ceritoglu E, Yunculer HBG, Torun H, Tumen S. The impact of Syrian refugees on natives' labor market outcomes in Turkey: evidence from a quasi-experimental design. IZA J Labor Policy. 2017;6:5. doi: 10.1186/ s40173-017-0082-4.

27. Nguyen AM, Wood SJ. The push-pull factors of physician-system integration: a qualitative study of Washington State Healthcare Executives. J Healthc Manag. 2019;64(1):15-26.

28. Valtonen K. The adaptation of Vietnamese refugees in Finland. J Refug Stud. 1994;7(1):63-78.

29. Bech P. Social functioning should it become an endpoint in trials of antidepressants? CNS Drugs. 2005;19(4):313-24.

30. Cousins S. Syrian crisis: health experts say more can be done. Lancet. 2015;385(9972):931-4. 